\title{
STRES DAN STRATEGI DAYA TINDAK DALAM KALANGAN PELAJAR PROGRAM TRANSFORMASI DIRI (PTD) DI INSTITUT PENDIDIKAN GURU KAMPUS PULAU PINANG (IPGKPP)
}

\section{(STRESS AND COPING STRATEGIES AMONG PROGRAM TRANSFORMASI DIRI [PTD] STUDENTS AT THE INSTITUTE OF TEACHER EDUCATION PULAU PINANG CAMPUS)}

\author{
Mohamad Faizel Ali ${ }^{1 *}$ and Nor Shafrin Ahmad ${ }^{2}$ \\ ${ }^{1}$ Psychology and Counselling Unit, Institute of Teacher Education Penang Campus, \\ Bukit Coombe, 11700 Gelugor, Pulau Pinang, Malaysia \\ ${ }^{2}$ School of Educational Studies, Universiti Sains Malaysia, \\ 11800 USM Pulau Pinang, Malaysia \\ *Corresponding author: mohamadfaizel.ali@gmail.com
}

Publication date: 23 December 2020

To cite this article: Mohamad Faizel Ali, \& Nor Shafrin Ahmad. (2020). Stres dan strategi daya tindak dalam kalangan pelajar Program Transformasi Diri (PTD) di Institut Pendidikan Guru Kampus Pulau Pinang (IPGKPP). Asia Pacific Journal of Educators and Education, 35(2), 77-87. https://doi.org/10.21315/apjee2020.35.2.5

To link to this article: https://doi.org/10.21315/apjee2020.35.2.5

\begin{abstract}
The Malaysian Institute of Teacher Education (IPGM) has designed a comprehensive teacher training program for Sijil Pelajaran Malaysia (SPM) graduates, by using competitive teacher training program that in line with the needs of the globalisation era. However, this teacher training program is challenged when there are cases of suicide as well as an increase in dropout cases using IPGM students. This study aims to identify the level of stress and coping strategies among students of the Program Transformasi Diri (PTD) according to gender and course options taken at Institut Pendidikan Guru Kampus Pulau Pinang (IPGKPP). A total of 41 respondents consisting of 21 male students and 20 female students. Respondents in this study were selected based on the purpose of sampling method that is the study respondents should consist of participants from the PTD organised by the Psychology and Counseling Unit IPGKPP. This study used a questionnaire to collect responses from respondents based on two questionnaires used namely Depressive Anxiety and Stress Scales 42-item (DASS-42) Malay Version for measuring the level of
\end{abstract}


stress and Inventori Strategi Daya Tindak (ISDT) to identify strategies responsiveness of the respondents of this study. The results showed that the study respondents were at a mild and moderate level of stress. Furthermore, the findings of the study also show that there is no significant difference between gender factors as well as study options with the level of stress faced. In addition, the findings also show that the study respondents are more likely to use engagement strategies that show the ability to manage the problems they face. As a result of the findings obtained, the researcher suggested that there should be a specific program provided related to stress management skills in the study of IPGM trainee teachers who pay attention to aspects of coping strategies in an effort to address the stress faced.

Keywords: Stress, coping strategies, teachers trainee, Malaysian Institute of Teacher Education, Program Transformasi Diri (PTD)

\begin{abstract}
Abstrak: Institut Pendidikan Guru Malaysia (IPGM) telah merangka program latihan perguruan yang komprehensif untuk lepasan pelajar Sijil Pelajaran Malaysia (SPM), dengan membina program latihan perguruan yang berdaya saing dan mengikut keperluan zaman globalisasi. Namun, program latihan perguruan ini tercabar apabila terdapat kes bunuh diri serta peningkatan kes berhenti dari pengajian yang melibatkan pelajar IPGM. Kajian ini bertujuan untuk mengenal pasti tahap stres dan strategi daya tindak dalam kalangan pelajar IPGM khususnya kepada populasi kajian yang terdiri dari pelajar-pelajar Program Transformasi Diri (PTD) Institut Pendidikan Guru Kampus Pulau Pinang (IPGKPP). Seramai 41 orang responden yang terdiri dari 21 orang pelajar lelaki dan 20 orang pelajar perempuan. Responden dalam kajian ini dipilih berdasarkan kaedah persampelan bertujuan iaitu responden kajian perlu terdiri dari peserta dari PTD yang dianjurkan oleh Unit Psikologi dan Kaunseling IPGKPP. Kajian ini menggunakan kaedah soal selidik untuk mengumpul jawapan terus responden berdasarkan dua soal selidik yang digunakan iaitu Depressive Anxiety and Stress Scales 42-item (DASS-42) versi Bahasa Melayu untuk mengukur tahap stres serta Inventori Strategi Daya Tindak (ISDT) untuk mengenal pasti strategi daya tindak responden kajian ini. Hasil dapatan kajian menunjukkan responden kajian berada pada tahap stres yang ringan dan sederhana. Seterusnya, dapatan kajian turut menunjukkan tidak terdapat perbezaan yang ketara antara faktor jantina serta opsyen pengajian dengan tahap stres yang dihadapi. Selain itu, dapatan kajian turut menunjukkan responden kajian lebih cenderung menggunakan strategi daya tindak engagement iaitu menunjukkan kemampuan untuk menguruskan masalah yang dihadapi oleh mereka. Hasil dari dapatan kajian ini mendapati perlu ada satu program khusus disediakan berkaitan kemahiran pengurusan stres dalam kajian guru pelatih IPGM yang memberi perhatian terhadap aspek-aspek strategi daya tindak sebagai usaha untuk menangani stres yang dihadapi.
\end{abstract}

Kata Kunci: Stres, strategik daya tindak, guru pelatih, Institut Pendidikan Guru Malaysia, Program Transformasi Diri 


\section{PENGENALAN}

Stres telah menjadi topik yang kerap dibincangkan di persekitaran akademik dan masyarakat pada masa kini (Josep \& Caterina, 2013). Pusat pengajian tinggi merupakan satu persekitaran unik yang sering kali menuntut pelajar menyeimbangkan peranan dan tugas yang perlu dilaksanakan oleh mereka (Mastura, Fadilah, \& Nor Akmar, 2007). Sekiranya pelajar gagal membuat penyesuaian terhadap perubahan yang dihadapi, kemungkinan mereka akan gagal dalam melengkapkan pengajian yang sedang diikuti. Menurut Ferlis, Rosnah, Lailawati dan Surianti (2015), stres bukan sahaja dialami oleh orang dewasa, malahan turut dialami oleh pelajar di pusat pengajian tinggi kerana universiti atau pusat pengajian tinggi mempunyai persekitaran unik yang seringkali menuntut pelajar menyeimbangkan pelbagai peranan dan tugas yang perlu dilaksanakan.

Kashif, Shazia dan Farzan (2013) menyatakan bahawa masalah stres dalam kalangan pelajar pengajian tinggi berpunca daripada empat tekanan utama dalam kehidupan iaitu tekanan keluarga, tekanan emosi, tekanan kewangan dan tekanan sosial. Semua tekanan ini akan mengganggu kefungsian hidup pelajar. Keadaan stres akan memberi kesan negatif terhadap kesihatan fizikal dan mental, prestasi akademik termasuk semua aspek kehidupan keseluruhannya jika tidak dapat diuruskan dengan baik.

Setiap individu mempunyai cara atau kaedah tersendiri dalam mengatasi masalah stres yang dihadapi. Menurut Shamsaadal et al. (2017), stres sepatutnya dapat membangkitkan semangat juang yang tinggi dalam diri pelajar bagi mencapai matlamat yang telah ditetapkan jika ia diuruskan dengan baik. Golongan pelajar seharusnya bijak dalam mengatur dan mencari jalan penyelesaian bagi mengatasi masalah yang dihadapi. Kemahiran strategi daya tindak amat diperlukan sebagai penyelesaian kepada situasi yang menekan. Pendekatan kognitif atau tingkah laku sering digunakan dalam usaha untuk mengawal atau mengurangkan permasalahan stres ini (Ferlis et al., 2015).

Kajian ini bertujuan untuk mengenal pasti tahap stres dan strategi daya tindak yang sering digunakan oleh pelajar-pelajar yang mengikuti Program Transformasi Diri (PTD). PTD merupakan satu program khas yang diwujudkan oleh Unit Psikologi dan Kaunseling (UPsK) dengan kerjasama Unit Peperiksaan dan Penilaian, Institut Pendidikan Guru Kampus Pulau Pinang (IPGKPP) dalam usaha untuk membantu pelajar-pelajar yang tidak mendapat keputusan yang baik semasa peperiksaan akhir. Matlamat utama PTD ini adalah untuk membantu pelajar yang terlibat dalam merancang semula kaedah pembelajaran serta pengurusan masa. 
Selain itu, pelbagai aktiviti dan pengisian telah dirancang oleh UPsK IPGKPP untuk membantu pelajar-pelajar ini, antaranya bengkel pengurusan masa dan stres, bengkel terapi pengurusan stres serta perjumpaan berkala menggunakan pendekatan kaunseling kelompok.

\section{Objektif Kajian}

Kajian ini dilaksanakan untuk mengenal pasti (i) tahap stres pelajar PTD, (ii) perbezaan tahap stres pelajar PTD berdasarkan jantina, (iii) perbezaan tahap stres pelajar PTD berdasarkan kursus, dan (iv) strategi daya tindak yang sering digunakan pelajar PTD.

\section{PENYATAAN MASALAH}

Dalam usaha melahirkan guru yang kompeten dan berjiwa pendidik serta mampu bersaing di peringkat antarabangsa, Institut Pendidikan Guru Malaysia (IPGM) telah merangka beberapa program latihan perguruan yang komprehensif untuk lepasan pelajar Sijil Pelajaran Malaysia (SPM), iaitu Program Persediaan Ijazah Sarjana Muda Perguruan (PPISMP) dan Program Ijazah Sarjana Muda Perguruan Dengan Kepujian (PISMP). IPGM telah membina program latihan perguruan yang berdaya saing dan mengikut keperluan zaman globalisasi.

Namun, program latihan perguruan ini dipertikaikan oleh sesetengah pihak apabila berlaku kejadian bunuh diri seorang pelajar guru di salah sebuah Institut Pendidikan akibat mengalami stres yang kritikal pada 4 April 2018. Begitu juga terdapat peningkatan kes berkaitan masalah stres dan kemurungan dalam kalangan pelajar IPGM di 27 buah kampus sekitar Malaysia. Contohnya pada tahun 2017, terdapat dua kes melibatkan pelajar guru yang terpaksa menangguhkan pengajian kerana mengalami tekanan yang kritikal di salah sebuah kampus di utara Malaysia (Abd Latib, Shuhailah, \& Kamil, 2019). Selain daripada itu, terdapat banyak kes yang dilaporkan berkaitan pelajar ingin berhenti belajar kerana mengalami stres yang tinggi. Menurut Lin dan Huang (2014), stres yang tinggi akan membahayakan seseorang itu, termasuk pelajar yang menuntut di pusat pengajian tinggi.

Terdapat beberapa kajian berkaitan masalah stres dalam kalangan pelajar IPGM yang telah dijalankan. Hasnah (2016) telah menjalankan kajian berkaitan stres dalam kalangan pelajar IPGM semasa latihan praktikum. Beliau mendapati kurangnya program persediaan pengurusan stres serta kemahiran daya tindak terhadap pelajar IPGM yang menyebabkan mereka mudah berasa stres dan tidak 
dapat memberi perkhidmatan yang terbaik semasa latihan praktikum. Dalam pada itu, hasil kajian Gopal, Donatus dan Francis (2010) berkaitan tahap dan punca stress dalam kalangan pelajar PISMP di Institut Pendidikan Guru (IPG) Keningau pula mendapati stres pelajar berada pada tahap yang sederhana. Hasil kajian turut mendapati aspek akademik dan pembelajaran menjadi faktor stres yang paling dominan dalam kalangan pelajar. Hasil kajian turut mencadangkan agar satu program intervensi melibatkan kemahiran pengurusan stres serta kemahiran membuat keputusan dapat dijalankan dalam membantu pelajar yang menghadapi masalah ini.

Setiap individu mempunyai cara atau kaedah tersendiri dalam mengatasi masalah stres yang dihadapi. Usaha individu untuk mengatasi stres ini dikenali sebagai strategi daya tindak (Ferlis et al., 2015). Strategi daya tindak merupakan usaha yang menggunakan tingkah laku untuk menyelesaikan pelbagai tuntutan yang dihasilkan oleh stres (Lazarus, 2000). Salhah, Sapora, Dini dan Rezki (2011) melihat daya tindak sebagai tindakan yang spesifik yang berupaya membantu perubahan dalam diri seseorang. Strategi daya tindak juga sering kali dikaitkan dengan emosi yang positif dan emosi ini kebiasaannya terhasil daripada individu itu sendiri (Philippe, Lecours, \& Bealieu-Pelletier, 2009).

Sehubungan dengan itu, Prabhat (2014) mencadangkan penekanan kemahiran strategi daya tindak dalam program-program berkaitan pengurusan stres. Modulmodul yang dihasilkan perlu memberi penekanan kepada aspek Problem Focused Coping Strategies berbanding Emotion Focused Coping Strategies, berdasarkan Teori Stres Lazarus dan Folkman (1984). Cadangan ini disokong oleh Gurjot Kaur (2017), yang menyatakan jika seseorang individu kurang menggunakan strategi daya tindak Problem Focused dalam menyelesaikan masalah kehidupan harian, besar kemungkinan individu tersebut mudah mendapat stres. Alishia (2014) turut membuat kajian berkaitan kelebihan menggunakan Engagement coping (Adaptive coping strategies) dalam menguruskan masalah stres dan kemurungan. Beliau mendapati engagement coping memberikan kesan langsung menyelesaikan masalah dalam pengurusan kemahiran daya tindak individu berbanding disengagement coping (Maladaptive coping strategies) yang lebih kepada penafian serta penarikan diri dari masalah yang dihadapi.

Oleh yang demikian, satu kajian perlu dijalankan bagi mengenal pasti tahap stres serta strategi daya tindak yang sering digunakan dalam menangani masalah yang dihadapi oleh pelajar IPGM. Maka dapat disimpulkan bahawa perlu ada satu strategi atau tindakan penyelesaian dalam membantu pelajar yang mengalami masalah stres terutamanya kepada pelajar di IPGM. 


\section{METODOLOGI KAJIAN}

\section{Rekabentuk Kajian}

Kajian ini merupakan satu kajian yang menggunakan pendekatan kuantitatif. Kajian ini menggunakan soal selidik untuk mendapatkan data primer daripada 41 pelajar guru yang menjadi sampel kajian. Kaedah soal selidik ini mengumpulkan jawapan terus dari subjek kajian, data dapat dikutip dengan cepat dan keupayaan keputusan kajian untuk digeneralisasikan kepada populasi dengan tepat dan berkesan (Chua, 2014). Data kuantitatif dianalisis menggunakan perisian SPSS versi 20 untuk mendapatkan min, sisihan piawai, peratusan dan kekerapan.

\section{Populasi dan Sampel Kajian}

Kajian ini menggunakan kaedah persampelan bertujuan kerana menggunakan keseluruhan sampel kajian yang dipilih dalam kalangan pelajar yang mengikuti program PTD di IPGKPP, iaitu seramai 41 orang. Sampel kajian terdiri daripada guru pelatih dari program PPISMP dan PISMP. Seramai 21 orang guru pelatih lelaki dan 20 orang guru pelatih perempuan terlibat dalam kajian ini.

\section{Pengumpulan Data}

Soal selidik yang digunakan dalam kajian ini ialah Depressive Anxiety and Stress Scales 42-item (DASS-42) versi bahasa Melayu yang telah diterjemah oleh Ramli, Ariff dan Zaini (2007). Soal selidik ini mempunyai nilai kebolehpercayaan 0.94 dan nilai kesahan 0.95. DASS-42 mengandungi tiga konstruk utama iaitu kemurungan, kebimbangan dan stres. Oleh kerana kajian ini hanya untuk melihat tahap stres dalam kalangan sampel, hanya item-item dalam konstruk stres sahaja digunakan dengan membuat semula ujian kebolehpercayaan (reliability test). Hasil ujian kebolehpercayaan untuk 14 item stres dalam soal selidik ini menunjukkan nilai alfa Cronbach ialah 0.818, iaitu melebihi 0.5.

\section{Inventori Strategi Daya Tindak (ISDT)}

Inventori ini digunakan untuk mengenal pasti strategi daya tindak yang digunakan oleh sampel kajian ini. Inventori ini merupakan adaptasi dari Coping Strategies Inventory (CSI) oleh Cano Garcia, Rodrigus Franco dan Garcia Martinez (2007). CSI telah diadaptasikan ke Bahasa Melayu oleh Salhah et al. (2011). ISTD mempunyai nilai kebolehpercayaan sederhana tinggi bagi setiap faktor dan secara keseluruhannya nilai alfa Cronbach adalah di antara 0.62 dan 0.75 dan nilai kesahan adalah tinggi iaitu 0.93 . 


\section{DAPATAN KAJIAN}

\section{Mengenal Pasti Tahap Stres Pelajar PTD}

Jadual 1 menunjukkan kekerapan dan peratusan tahap stres pelajar PTD. Sebanyak 41 responden terlibat dalam kajian ini, di mana 15 responden atau $36.6 \%$ menunjukkan tahap stres normal, 10 responden (24.4\%) menunjukkan tahap stres ringan, 14 responden (34.1\%) menunjukkan tahap stres sederhana manakala dua responden atau sebanyak $4.9 \%$ menunjukkan tahap stres yang teruk.

Jadual 1. Tahap stres pelajar PTD

\begin{tabular}{lcc}
\hline Tahap stres & Kekerapan & $\%$ \\
\hline Normal & 15 & 36.6 \\
Ringan & 10 & 24.4 \\
Sederhana & 14 & 34.1 \\
Teruk & 2 & 4.9 \\
Jumlah & 41 & 100 \\
\hline
\end{tabular}

\section{Mengenal Pasti Perbezaan Tahap Stres Pelajar PTD Berdasarkan Jantina}

Berdasarkan Jadual 2, didapati nilai- $t$ bagi perbandingan tahap stres dalam kalangan pelajar PTD berdasarkan jantina ialah $t=0.149$ dan tahap signifikan $p=0.488$. Tahap signifikan ini lebih besar daripada $0.05(p>0.05)$. Oleh yang demikian, tidak terdapat perbezaan yang signifikan bagi tahap stres dalam kalangan pelajar PTD berdasarkan jantina. Skor min tahap stres pelajar perempuan $(\min =2.050)$ adalah lebih kecil berbanding pelajar lelaki $(\mathrm{min}=2.095)$. Ini bermakna tahap stres pelajar lelaki dan perempuan dalam PTD adalah sama.

Jadual 2. Perbezaan tahap stress pelajar PTD berdasarkan jantina

\begin{tabular}{lccccc}
\hline Jantina & $N$ & Min & Sisihan piawai & Nilai $t$ & Tahap signifikan \\
\hline Lelaki & 21 & 2.095 & 0.995 & 0.149 & 0.488 \\
Perempuan & 20 & 2.050 & 0.944 & & \\
\hline
\end{tabular}

\section{Mengenal Pasti Perbezaan Tahap Stres Pelajar PTD Mengikut Kursus}

Berdasarkan Jadual 3, didapati nilai $t$ bagi perbandingan tahap stres dalam kalangan pelajar PTD berdasarkan kursus ialah $t=0.472$ dan tahap signifikan $p=0.846$. Tahap signifikan ini lebih besar daripada $0.05(p>0.05)$. Oleh yang demikian, tidak terdapat perbezaan yang signifikan bagi tahap stres dalam kalangan 
pelajar PTD berdasarkan kursus. Skor min tahap stres pelajar kursus Matematik $(\min =2.000)$ adalah lebih kecil berbanding pelajar kursus Sains $(\min =2.142)$. Ini bermakna tahap stres pelajar kursus Matematik dan Sains dalam PTD adalah sama.

Jadual 3. Tahap stress pelajar PTD berdasarkan kursus

\begin{tabular}{lccccc}
\hline Kursus & N & Min & Sisihan piawai & Nilai t & Tahap signifikan \\
\hline Matematik & 20 & 2.000 & 0.973 & 0.475 & 0.846 \\
Sains & 21 & 2.142 & 0.953 & & \\
\hline
\end{tabular}

\section{Strategi Daya Tindak yang Sering Digunakan oleh Pelajar PTD}

Strategi ini terbahagi kepada tiga sub-skala iaitu sub-skala primer, sub-skala sekunder dan sub-skala tertier.

\section{Sub-skala primer}

Sub-skala primer terbahagi kepada: penyelesaian masalah (problem solving) sebanyak enam responden, penstrukturan kognitif (cognitive restructring) seramai sembilan responden, sokongan sosial (social support) seramai 15 responden, mengelakkan diri daripada masalah (problem avoid) seramai dua responden, angan-angan (wishful thinking) seramai lima responden, kritik diri (self critism) seramai dua responden dan anti sosial (social withdraw) seramai dua responden.

\section{Sub-skala sekunder}

Sub-skala sekunder terbahagi kepada empat: pengurusan berfokuskan masalah (problem focused engagement) melibatkan 15 responden, pengurusan berfokuskan emosi (emotion focused engagement) melibatkan seramai 15 responden, ketidakmampuan mengurus berfokuskan masalah (problem focused disengagement) melibatkan tujuh responden dan ketidakmampuan mengurus berfokuskan emosi (emotion focused disengagement) seramai empat responden.

\section{Sub-skala tertier}

Dipecahkan kepada dua iaitu kemampuan mengurus (engagement) dan ketidakmampuan mengurus (disengagement). Dalam kajian ini, sub-skala tertier bagi kemampuan mengurus adalah sebanyak 27 responden manakala ketidakmampuan mengurus adalah sebanyak 14 responden. Data adalah seperti dalam Jadual 4. 
Jadual 4. Strategi daya tindak pelajar PTD

\begin{tabular}{lcc}
\hline Jenis strategi daya tindak & Kekerapan & Peratusan (\%) \\
\hline Kemampuan mengurus (Engagement) & 27 & 65.9 \\
Ketidakmampuan mengurus (Disengagement) & 14 & 34.1 \\
\hline Jumlah & 41 & 100 \\
\hline
\end{tabular}

\section{PERBINCANGAN}

Hasil kajian yang diperolehi menunjukkan tahap stres pelajar PTD berada pada tahap stres ringan dan sederhana. Hasil dapatan ini selaras dengan kajian yang telah dijalankan oleh Gopal et al. (2010) yang mendapati ramai guru pelatih di IPG Kampus Keningau mengalami stres pada tahap yang sederhana. Hasil kajian Gopal et al. (2010) juga mendapati aspek akademik dan pembelajaran menjadi faktor stres yang paling dominan dalam kalangan pelajar.

Dalam masa yang sama, hasil dapatan kajian ini turut menunjukkan tiada perbezaan tahap stres yang ketara di antara peserta lelaki dan perempuan. Hasil dapatan kajian turut mendapati tiada perbezaan yang ketara antara faktor stres berdasarkan kursus yang diikuti di kampus. Hasil dapatan kajian ini bertepatan dengan kajian yang telah dijalankan oleh Shamsaadal et al. (2017) yang mendapati, setiap pelajar di pusat pengajian tinggi tidak kira lelaki atau perempuan berpotensi untuk berhadapan dengan masalah stres hasil dari interaksi faktorfaktor seperti sosial, akademik, kewangan, emosi dan perhubungan.

Kemahiran strategi daya tindak yang sering digunakan oleh pelajar PTD dikaji berdasarkan tiga sub-skala yang terdapat dalam ISDT. Dapatan kajian menunjukkan sub-skala primer memperolehi skala tertinggi bagi sokongan sosial (social support), iaitu seramai 15 responden. Ini menunjukkan kebanyakan responden memerlukan sokongan dalam membuat keputusan bagi mengurangkan masalah stres mereka. Seterusnya, dalam sub-skala sekunder lebih ramai responden kajian cenderung menggunakan Pengurusan Berfokuskan Masalah (Problem Focused Engagement) berbanding Pengurusan Berfokuskan Emosi (Emotion Focused Engagement). Ini menunjukkan responden berusaha untuk menyelesaikan masalah yang dihadapi dengan membuat perancangan tindakan terlebih dahulu. Dapatan kajian ini selaras dengan kajian yang telah dijalankan oleh Gurjot Kaur (2017) yang menyatakan jika individu kurang menggunakan strategik daya tindak Problem Focused dalam menyelesaikan masalah kehidupan seharian, besar kemungkinan individu tersebut mudah mengalami stres. 
Akhir sekali, hasil dapatan dalam sub-skala primer dan sekunder telah mempengaruhi dapatan dalam sub-skala tertier. Hasil dapatan sub-skala tertier pula telah dibahagikan kepada dua iaitu kemampuan mengurus atau engagement dan ketidakmampuan mengurus atau disengagement. Responden kajian lebih cenderung menggunakan strategi daya tindak engagement iaitu menunjukkan kemampuan untuk menguruskan masalah yang dihadapi oleh mereka. Alishia (2014) turut membuat kajian berkaitan kelebihan penggunaan engagement coping (Adaptive Coping Strategies) dalam menguruskan masalah stres dan kemurungan. Beliau mendapati engagement coping memberi kesan langsung menyelesaikan masalah dalam pengurusan kemahiran daya tindak individu berbanding disengagement coping (Maladaptive Coping Strategies) yang lebih kepada penafian serta penarikan diri dari masalah yang dihadapi.

\section{KESIMPULAN}

Hasil dari dapatan kajian yang dijalankan, dapat disimpulkan bahawa perlu ada satu strategi atau tindakan penyelesaian dalam membantu pelajar yang mengalami masalah stres di Institut Pendidikan Guru Kampus Pulau Pinang. Kajian ini memberi maklumat awal kepada pihak pentadbiran IPGM untuk merangka suatu program pengurusan stres yang memberi perhatian khusus berkaitan kemahiran strategik daya tindak. Program yang dirangka perlu mengambil kira faktor kepadatan kuliah serta jadual pengajian pelajar tanpa mengganggu perjalanan kuliah seharian. Oleh yang demikian, program pengurusan stres yang dirangka perlu mengunakan pendekatan yang sesuai dengan persekitaran pengajian IPGM serta dapat menangani masalah stres secara berkesan.

\section{RUJUKAN}

Abd. Latib, A. R., Shuhailah, S., \& Kamil, N. (2019). Kajian stres dalam kalangan pelajar guru di Institut Pendidikan Guru Kampus Pulau Pinang. Paper presented at Seminar Penyelidikan IPGM 2019, IPG Kampus Dato Razali Ismail, 15-16 April.

Alishia, D. F. (2014). Traumatic life events and symptoms of anxiety: Moderating effects of adaptive versus maladaptive coping strategies. Unpublished Master thesis, East Tennessee State University.

Cano Garcia, F. J., Rodrigus Franco, L., \& Garcia Martinez, J. (2007). Spanish version of the coping strategies inventory. Actas Españolas de Psiquiatría, 35(1), 29-39.

Chua, Y. P. (2014). Kaedah dan statistik penyelidikan (3rd ed.). Shah Alam: Mcgraw-Hill Education. 
Ferlis Bullare@ Bahari, Rosnah Ismail, Lailawati Madlan@ Endalan, \& Surianti Lajuma. (2015). Strategi daya tindak remaja sekolah dan hubungannya dengan kemurungan. Jurnal Psikologi Malaysia 29(1), 21-38.

Gopal, V., Donatus, J., \& Francis, A. C. (2010). Tahap dan punca stres dalam kalangan pelajar IPG Kampus Keningau. Paper presented at Seminar Penyelidikan Tindakan IPG Kampus Keningau (pp. 1-12).

Gurjot Kaur. (2017). Social support and problem solving coping as moderators of the relation between stress and life satisfaction. Unpublished Master thesis, Arizona State University.

Hasnah, A. (2016). Stres dalam kalangan pelajar PISMP semasa praktikum. Jurnal Pendidikan Dedikasi, 11, 146-160.

Josep, G. C. \& Caterina, C. (2013). Coping strategies and psychological well-being among teacher education students Coping and well-being in students. Euro Journal Psychology Education, 28, 1127-1140. https://doi.org/10.1007/s10212-012 $-0158-\mathrm{x}$

Kashif Ud Din Khan, Shazia Gulzar, \& Farzan Yahya. (2013). Crucial factors affecting stress: A study among undergraduates in Pakistan. International Journal of Asian Social Science, 3(2), 428-442.

Lazarus, R. (2000). Toward better research on stress and coping. American Psychologist, 55(6), 665-673. http://doi.org/10.1037//0003-066X.55.6.665

Lazarus, R., \& Folkman, S. (1984). Stress, appraisal and coping. New York: Springer Publishing Company.

Lin, S. H., \& Huang, Y. C. (2014). Life stress and academic burnout. Active Learning in Higher Education, 15(1), 77-90. https://doi.org/10.1177/1469787413514651

Mastura, M., Fadilah, Z., \& Nor Akmar, N. (2007). Analisis faktor penyebab stres di kalangan pelajar. Jurnal Kemanusiaan, 9, 62-72.

Philippe, F. L., Lecours, S., \& Bealieu-Pelletier, G. (2009). Resilience and positive emotions: Examining the role of emotional memories. Journal of Personality, 77(1), 140-176.

Prabhat, K. M. (2014). Stress and coping: Some critical issue. Indian Journal of Positive Psychology, 5(3), 341-343.

Ramli, M., Ariff, M. F., \& Zaini, Z. (2007). Translation, validation and psychometric properties of Bahasa Malaysia version of the Depression Anxiety and Stress Scales (DASS-21). ASEAN Journal of Psychiatry, 8(2), 82-89.

Salhah, A., Sapora, S., Dini Farhana, B., \& Rezki Perdani, S. (2011). Strategi daya tindak versi bahasa Melayu. Paper presented at the PERKAMA International Counseling Convention 2011, Isola Resort, Bandung, Indonesia, 7-9 December.

Shamsaadal, S., Zaimah, W. W. A, Zahrul, A., Harliana, H., Hussain, O., \& Khairul, A. (2017). Pengurusan stres dalam kalangan pelajar universiti. Batu Pahat, Johor: Penerbit Universiti Tun Hussein Onn Malaysia. 